\title{
Lead Placement Bipolar Uncorrected XYZ
}

National Cancer Institute

\section{Source}

National Cancer Institute. Lead Placement Bipolar Uncorrected XYZ. NCI Thesaurus.

Code C71121.

An electrocardiogram (ECG) lead placement whereby the X+ lead is placed at the right mid-axillary line at the 4th intercostal space, $X$ - at the left mid-axillary line at the 4th intercostal space, $\mathrm{Y}+$ at the proximal left leg, $\mathrm{Y}$ - at the superior aspect of the manubrium, Z+ at the direct posterior to Z- and Z- at the 4th intercostal space at the left sternal margin. 